\title{
Agências de Turismo: oferta de serviços e satisfação do cliente
}

de São Pauld.

\section{Tânia Veludo de Oliveira ${ }^{1}$ Ana Akemi Ikeda ${ }^{2}$}

RESUMO: Discute a importância dos serviços na oferta turística para a satisfação do cliente. Analisa o conceito de valor em serviços oferecidos, atra vés de pesquisa bibliográfica e estudo de caso em duas agências de viagens brasileiras.

PALAVRAS-CHAVE: oferta turística, agência de viagem, serviços, satisfação do cliente.

ABSTRACT: The present study discusses the role of services in the tourist supply to reach orexceed customer's expectations. This paperanalyses the theoretical research and two cases studies in Brazilian travel agencies.

KEYWORDS: tourist supply, travel agencies, services, client satisfaction.

\section{Introduçāo}

A reestruturação do mercado turístico, com o surgimento de novas tecnologias e concorrência acirrada, tem levado as agências de viagens a reordenarem suas estratégias na tentativa de obter maior competitividade. Tais empresas estão enfrentando grandes desafios no que se refere à adaptação ao ambiente globalizado. A popularização da Internet, por exemplo, está acentuando a rivalidade entre concor-

1. Mestranda do Programa de Pós-Graduação em Administração da Faculdade de Economia, Administração e Contabilidade (FEA), da Universidade de São Paulo. Professora da Escola de Comércio Álvares Penteado.

E-mail:tveludo@usp.br

2. ProfessoraLivre-Docente da Faculdade de Economia, Adıninistraçãoe Contabilidade (FEA), da Universidade deSão Paulo.

E-mail: anaikeda@usp.br 
rentes nacionais e internacionais ao proporcionar a entrada de novas empresas no setor e ao aumentar o poder de barganha dos fornecedorcs, propiciando negociação direta com os passageiros. A busca por diferenciação no mercado tem induzido algumas agências a incorporarem diversos tipos de serviços à sua oferta, procurando oferecer um padrão de atendimento que alcance ou supere as expectativas dos consumidores.

Este artigo discute a importância dos serviços na oferta turística, e tem como objetivo verificar, dentro de um contexto de transformação de mercado, procedimentos que podem ser usados pelas agências de viagens para obter a satisfação do cliente e, consequentemente, vantagens competitivas.

Em relação à metodologia, realizaram-se levantamento bibliográfico e um estudo de casos. A preocupação em criar serviços que satisfaçam o cliente é objeto de reflexão de muitos pesquisadores. O levantamento bibliográfico apresenta a abordagem de alguns autores em relação aos serviços para satisfação do cliente e, principalmente, ao conceito de valor. O estudo de casos envolve a análise comparativa dos serviços oferecidos por duas agências de viagens brasileiras - a CVC e a Stella Barros. Na seleção dessas empresas deu-se preferência para agências que realizam o papel de operadoras turísticas, desenvolvendo roteiros e pacotes para viagens; procurou-se também abordar agências localizadas na cidade de São Paulo, que utilizamos recursos dainternet para conduzirsuas estratégias de marketing, uma vez que a Internet é fator que tem provocado grandes impactos no setor.

\section{Serviços para Satisfaçāo do Cliente}

O caminho para a satisfação do cliente exige essencialmente a prestação de serviços superiores e pode envolver o incremento da oferta por meio da incorporação de serviços diferenciados e adaptações em serviços.

A prestação de serviços ao cliente tem sido sistematicamente enfocada na literatura mais recente de marketing como um dos elementos mais relevantes para o sucesso empresarial e a prática moderna de marketing (Machado, 1999: 12)

As empresas podem se diferenciar pelos serviços que oferecem, tornando-os atrativos e singulares. Mc Goldrick (1990: 322) aponta que 70\% dos consumidores não se importam em pagar um pouco mais quando o serviço é particularmente bom

A prestação de serviços com excelência traz vantagens competitivas às organizações, podendo causar sensações de satisfação e encantamento nos clientes, reduzir os níveis de risco percebidos na compra e proporcionar condições mais favoráveis à avaliação positiva da empresa. Todos esses aspectos contribuem para a competitividade organizacional, que tem como base as vantagens competitivas decorrentes da preferência e da satisfação dos consumidores.
As vantagens competitivas estão relacionadas ao valor que a empresa consegue criar para sua oferta. Albrecht (1995: 14) coloca que o que a empresa entrega ao cliente é um pacote de valor, resultante da combinação de fatores tangíveis, intangíveis e de experiências. Conforme enfatizam Kotler e Armstrong (1998: 6)

o valor para o cliente é a diferença entre os valores que ele ganha comprando e usando um produto e os custos para obter esse produto.

Com base nessas abordagens, é possível verificar que o conceito de valor está muito relacionado às expectativas e à forma com que são satisfeitas.

A satisfação dos consumidores somente pode ser alcançada quando há o processo apropriado para garantir que o serviço esteja de acordo com as necessidades e desejos do público-alvo. Lewis e Booms (1983: 99) reafirmam essa idéia ao colocar que

a qualidade do serviço é a medida de como o nível de entrega dos serviços combina com as expectativas dos consumidores.

Ainda sobre essa questão, Sudharshan (1995: 10-11) comenta que a satisfação e o encantamento dos consumidores estão baseados na lacuna entre expectativas e experiências e que as expectativas apresentam dois componentes, o primeiro referente à expectativa de troca a ser obtida e o segundo referente à expectativa de como eles serão tratados. Portanto, para realizar melhoramentos, inovações e adaptações em serviços capazes de agregar valor a oferta, a empresa deve reconhecer as expectativas de seu público e avaliar a relação custo-benefício das ações implementadas para atingir a essas expectativas. Sobre essa afirmação, Kotler, Bowen e Makens (1996: 343) argumentam que as empresas de serviços devem balancear o custo incorrido na melhora do núcleo do serviço em relação àquilo que os consumidores consideram para ser avaliado, para perceber se o consumidor está disposto a pagar para obter algum benefício extra. Complementando esse enfoque, Lovelock (1995: 77-78) afirma que

a maneira mais útil para definir o valor de um relacionamento é como a diferença liquida entre os fluxos de custos e os benefícios percebidos que este gera durante sua vida.

Em virtude da particularidade de suas características - intangível, perecível, heterogêneo, inseparável -, os serviços estão mais suscetíveis à avaliação subjetiva dos clientes, o que pode ocasionar dificuldades na avaliação do nívcl real de satisfação dos mesmos. Geralmente, um erro cometido na prestação de um serviço 
é notado em nível pessoal pelo cliente, trazendo fortes impactos negativos à avaliação da qualidade. Em função de tamanha complexidade, a implantação de serviços, que valorizem o relacionamento da empresa com o cliente, ć vista como grande desafio pelas organizações.

\section{Compreendendo as Expectativas do Cliente}

A oferta de serviços com excelência pressupõe uma rotina de trabalho que continuamente verifique a sua adequação perante o mercado. Pode-se dizer que intrinsecamente a excelência de uma oferta, há um processo coordenado e integrado que se preocupa em fazer melhorias, adaptações e inovações que estejam de acordo com as mudanças de comportamento do consumidor e com as alterações de estratégias da concorrência.

Segundo Berry (1995: 84), as organizações precisam estabelccer um sistema de informações sobre a qualidade do serviço, em vez de apenas realizar estudos isolados. $\mathrm{O}$ autor propõe que sejam realizadas, de forma complementar, pesquisas transacionais, pesquisas de mercado, “compra misteriosa", pesquisas com clientes novos, desistentes eex-clientes, entrevistas com grupos de foco e também relatórios de campo de funcionários, principalmente daqueles que lidam diretamente com o consumidor, já que eles possuem informações que muitas vezes não são captadas por outros meios.

Pride e Ferrel (2001: 42) alertam para a importância da Internet na atividade de monitoramento do mercado, uma vez que "ela torna os dados mais acessíveis e permite as empresas coletar rapidamente as informações necessárias". A Internet facilitou a implantação de canais de comunicação com o público geral, por meio da criação dos sites. Esses canais de comunicação permitem que a empresa capte as expectativas e percepções de seu público de uma forma mais simplificada, através do envio de sugestões, dúvidas, elogios e reclamações ao $e$-mail da companhia ou da participação em pesquisas disponibilizadas no site. As críticas representam uma fonte valiosa de informações para análise de oportunidades de mercado e para o estreitamento dos laços com o público.

Levitt (1995: 54) afirma que uma das indicações mais exatas de um relacionamento ruim ou em decadência é a ausência de queixas do cliente. Naturalmente, a empresa que não abre espaço para ouvir o seu público não conhece os seus pontos de vista e pode erroneamente supor, com base na ausência de reclamações, que ele esteja satisfeito. A falta de comunicação da empresa com o seu cliente é ao mesmo tempo sintoma e causa de problemas. Portanto, o primeiro passo para oferecer serviços com excelência ou incrementar a oferta por meio da incorporação de serviços, é conhecer as expectativas do cliente, o que pode ser facilitado pcla abertura de canais de comunicação da empresa com o mercado.
Incrementando e Valorizando a Oferta por

meio de Serviços

Os consumidores possuem percepções diferentes em relação aos serviços oferecidos pelas empresas. Um atributo que é considerado muito importante para determinado cliente, talvez não seja tão relevante para outro. Essa idéia refere-se ao conceito de valor de um produto ou serviço. Valor é o

mérito de uma determinada ação ou objeto em relação às necessidades de um individuo em um dado momento (Lovelock e Wright, 2001: 25).

Sheth, Mittal e Newman (2001: 74) consideram que

como as necessidades e desejos dos clientes não são idênticos, um produto ou serviço pode ter mais valor para uma pessoa e menos para outra, porque satisfaz melhor as necessidades e os desejos de um cliente que de outro.

As empresas devem estar atentas para reconhecer os atributos mais valorizados e os atributos essenciais da prestação de scrviços na opinião de seus clientes. Assim, as empresas podem aprimorar os pontos positivos da prestação de serviços e melhorar os pontos negativos, aproximando as condições de sua oferta às expectativas de seu público, na forma de serviços diferenciados e adaptações em serviços.

Serviços diferenciados adicionam valor à oferta e são, normalmente, oferecidos por poucas organizações. Surgem em decorrência de uma idéia criativa e devem ser capazes de distanciar a empresa dos concorrentes. É comum que as empresas procurem oferecer serviços diferenciados naformade serviços pós-venda.

Knecht, Leszinski c Weber (1993: 79-86) colocam que os serviços pósvenda agregam valor, tanto no aspecto do faturamento como na formação de expectativas positivas da empresa perantc o cliente. Os serviços pós-venda são as atividades e procedimentos realizados após a concretização da venda para manter criar vínculos, satisfazer consumidores e principalmente, para motivá-los a efetuar compras futuras com a empresa.

Adaptações em serviços constituem-se em ajustes realizados para melhor adequação do serviço ao ambiente e às necessidades, desejos c expectativas do consumidor. No caso das agências de viagens, uma das mais importantes adaptações que precisam ser feitas é com relação aos picos de alta e baixa temporada. Sasse

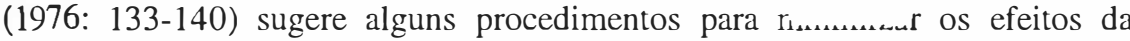
sazonalidade, por meio de adaptações em alguns serviços, tais como:

- ações para aumento da demanda nos períodos de baixa procura, como promoções e prática de preços diferenciados; 
- contratação de funcionários extras;

- incentivos à participação do cliente nas tarefas.

- oferta de serviços complementares durante o período de pico;

- implantação de sistemas de reservas, com o agendamento prévio de horários;

- estabelecimento de rotinas de eficiência, em que os funcionários desempenham apenas as funções essenciais e mais procuradas;

- compartilhamento de serviços, que envolve, por exemplo, o uso conjunto de equipamentos pelos funcionários.

\section{Avaliando o Valor dos Serviços}

A avaliação do valor dos serviços por parte dos clientes está relacionada ao nível de satisfação dos mesmos quanto a entrega total do serviço. Para Woodruff (1997: 142-143), a mensuração do valor por um cliente é feita segundo três níveis seqüenciais que se referem a diferentes dimensões de valores, são eles:

- valores associados aos objetivos e propósitos do cliente;

- valores associados ao desempenho esperado em situações de uso;

- valores associados aos atributos descjados do produto e ao desempenho desses atributos.

O autor sugere que o "grau de satisfação total em valor" seja resultante do valor esperado, formado pelas expectativas do cliente com relação às três dimensões citadas, e do valor recebido, formado pelo julgamento de conformidade entre as expectativas e desempenho, mais o benefício não esperado. $O$ benefício não esperado, por sua vez, é o resultado de uma ação de atendimento geradora de benefícios que não estava prevista na expectativa do cliente.

É possível estabelecer uma associação entre o modelo de Woodruff (1997) e o conceito de produto ampliado, proposto por Levitt (1980). Para Levitt (1980: 8391), a empresa deve considerar quatro níveis de produto ao planejar sua oferta, cm queos níveisobedecem a uma hierarquia, agregando maisvalor para o cliente quanto maior sua complexidade. O nível mais fundamental é chamado de produto básico, que se refere à oferta mínima que o cliente está comprando. No segundo nível está o produto esperado, que se refere a uma série de atributos que o cliente espera receber ao efetuar a compra. Já no terceiro nível tem-se o produto ampliado, que abrange os atributos da oferta que excedem às expectativas do cliente. No quarto e último nível está o produto potencial, que se refere às mudanças a que futuramente o produto será submetido para continuar ocupando espaço no mercado e agregando valor para o cliente.

Ainda com relação à idéia de avaliação e hierarquização de valor, assim como Woodruff (1997) e Levitt (1980), Albrecht (1995: 105) também propõe uma classificação que pode ser estendida para serviços. Essa classificação é chamada
Hierarquia de Atributos de Valor, segundo a qual o consumidor avalia os serviços prestados por uma empresa dentro de quatro níveis de serviços estabelecidos: básicos, esperados, desejados e inesperados. Os serviços básicos compreendem os atributos absolutamente essenciais procurados em um serviço. A sua ausência praticamente elimina a cmpresa do mercado. Esse é o caso dos serviços tradicionais oferecidos pelas agências de viagens, tais como pacotes e passagens aéreas. Já os serviços esperados compreendem os atributos associados à experiência que o cliente acostumou-se a considerar como fazendo parte da prática geral de negócios. A ausência desse atributo cria dificuldades para a empresa comercializar seu produto ou serviço. Podemos citar, como exemplo, o desconto dado às passagens aéreas para estudantes por agências especializadas nesse segmento. Os serviços desejados compreendem os atributos que o cliente não espera necessariamente receber, mas aprecia e valoriza se a experiência o incluir. A prática desses atributos começa a diferenciar a empresa no mercado como aquela que se preocupa com o cliente e dependendo das práticas dos concorrentes, pode ser fonte de vantagens competitivas. Isso ocorre com os serviços de copa, caixa automático e manobrista oferecidos por algumas agências de viagens. Por fim, os serviços inesperados compreendem aributos "surpresa", que adicionam valor à oferta, além dos desejos e expectativas dos clientes. A prática desses atributos induz ao encantamento, gerando clientes satisfeitos e fiéis. Nessa situação, enquadram-se as agências que, por exemplo, oferecem um cartão de desconto para uso em restaurantes do destino turístico ou seguros-viagens de cortesia.

Considerando o modelo de Albrecht (1995) e com base nas propostas de Woodruff (1997) e Levitt (1980), é importante ressaltar que deve haver um processo contínuo de busca por serviços que atendam às expectativas dos consumidores em todos os níveis, sendo mais difícil para a empresa encontrar serviços capazes de atender aos níveis desejados e inesperados. A Hierarquia de Atributos de Valor permite à empresa refletir sobre os níveis de serviços que está oferecendo aos clientes: quanto mais serviços inesperados forem oferecidos, maior a chance de obter clientes satisfeitos e fiéis.

\section{Análise do Estudo de Casos: Stella Barros e CVC}

A seguir, apresentam-se os principais resultados obtidos com o estudo de casos das agências de viagens Stella Barros e CVC; traça-se o perfil dessas agências. e procura-se compreender o processo adotado por essas empresas para melhoria, adaptação e inovação em serviços. Esse processo envolve a compreensão das necessidades dos clientes e a transformação de tais necessidades em serviços diferenciados, serviços pós-venda e outras adaptações. Finalmente, apresenta-se a classificação do valor dos serviços oferecidos pelas agências, segundo o modelo de Albrecht (1995). 


\section{Apresentando as Empresas}

As empresas pesquisadas estão entre as maiores agências de viagens brasileiras. Suas estruturas, quanto ao número de funcionários e número de filiais, são similares. Apesar da diversidade de produtos oferecidos, a CVC concentra seu negócio na oferta de viagens nacionais e a Stella Barros em viagens internacionais, especificamente para o destino Disney World. O perfil do cliente de tais empresas difere um pouco, pois, apesar de ser considerado muito exigente, o cliente da CVC é mais sensível a preços e o da Stella Barros se mostra mais fiel à empresa. As principais informações sobre as empresas pesquisadas podem ser observadas na tabela 1.

TABELA 1-PERFIL DAS AGÊNCIAS DE VIAGENS PESQUISADAS

\begin{tabular}{|c|c|c|}
\hline ঝ & STELLABAFROS & cko \\
\hline Ano de fundação & 1971 & 1973 \\
\hline Número de funcionários & 250 & 300 \\
\hline Franquias ( $n^{\circ}$ de lojas) & 32 & 22 \\
\hline Sede & Barueri-SP & Santo André - SP \\
\hline Ramo de negócio & $\begin{array}{l}\text { Roteiros intemacionais, } \\
\text { nacionais e viagens } \\
\text { corporativas }\end{array}$ & $\begin{array}{l}\text { Roteiros internacionais e } \\
\text { nacionais }\end{array}$ \\
\hline Perfil geral do cliente & Fiel e exigente & $\begin{array}{l}\text { Sensivel a preços } \\
\text { e exigente }\end{array}$ \\
\hline Core business & Viagens internacionais & Viagens nacionais \\
\hline Site & www.stellabarros.com.br & www.viagenscvc.com.br \\
\hline
\end{tabular}

\section{Compreendendo as Expectativas dos Clientes}

As agências pesquisadas apresentam condições e recursos para perceber o que seus consumidores desejam, pois possuem vários canais de contato para o cliente dar as sugestões e fazer as reclamações. Além de alguns canais estarem constantemente a disposição do cliente, as agências ainda fazem pesquisas de avaliação de serviços após a viagem do passageiro, estimulando-o a contribuir com sugestões para a melhora dos serviços como um todo. Os canais utilizados pelas agências para saber quais são as expectativas de seus consumidores são:

- pesquisa de satisfação após a viagem;

- monitoramento do setor, que envolvc o acompanhamento das açōes da concorrência;

- sugestões em sites;
- pesquisas de mercado realizadas por institutos especializados

- conversas informais nas lojas das agências, que contam com o auxílio dos funcionários da linha de frente.

\section{Incrementando e Valorizando Serviços}

Além dos serviços e produtos convencionais oferecidos pelas empresas do setor, as agências pesquisadas procuram oferecer diferenciais em serviços, para que seus clientes continuem fiéis e que a possibilidade de mudança de fornecedor seja minimizada.

As agências analisadas, de um modo geral, procuram transformar as necessidades percebidas e declaradas de seus clientes em serviços efetivos. É possível verificar exemplos de serviços implantados para minimizar problemas percebidos no atendimento e para melhorar a entrega da oferta ao cliente.

Pensando em minimizar o desconforto da fila de espera para o atendimento, a CVC começou a investir em filiais de shopping centers. No shopping é possível diversificar as opções do cliente. Se houver fila, o cliente recebe uma senha com um horário marcado para retorno. Enquanto espera seu horário de atendimento, ele pode aproveitar outros serviços do shopping. Outra iniciativa da CVC, para minimizar os efeitos da falta de tempo do cliente, foi o serviço de entrega de roteiros:

- por $e$-mail, em que os materiais são enviados para os correios eletrônicos dos passageiros;

- por portadores, que levam materiais, prospectos e passagens na casa do passageiro;

- por meio de promotores, que explicam os roteiros turísticos, prestando um atendimento na casa do passageiro.

Segundo a Stella Barros, o cliente tem expectativas em relação à qualidade das informações que recebe para viajar. Essa necessidade é decorrente da insegurança causada pela intangibilidade do produto turístico, que não pode ser visto ou tocado. Conhecendo essa necessidade e procurando oferecer um serviço diferenciado, a Stella Barros prepara um material personalizado com informações adicionais que possam agradar ao cliente segundo suas características pessoais. Assim, a Stella Barros procura oferecer uma personalização do atendimento, contando para isso com recursos de um banco de dados que também proporciona ações de marketing de pos-venda.

O serviço pós-venda, muito utilizado pelas empresas para diferenciar a sua oferta dos concorrentes, é muitas vezes proporcionado pelo controle que a empresa mantém sobre o cadastro de seus clientes, sendo possível recorrer ao histórico dos passageiros para manter uma comunicação personalizada, enviando-lhes materiais de seus interesses. 
As agências pesquisadas fazem a atualização de seus cadastros de forma espontânea, à medida que estabelecem novos contatos com os clientes, quer seja pela compra de um novo produto quer apenas pelo retorno de uma mala dircta enviada. O cadastro dos clientes está disponível na tela do computador para os funcionários de ambas agências quando é realizado o atendimento.

A Stella Barros faz o acompanhamento do perfil de cada cliente, os dados dos passageiros, recolhidos pela central de atendimento ou pela Internet, são usados para envio de malas diretas focalizadas nas preferências de cada passageiro. A Stella Barros faz ligações telefônicas quando há produtos que possam interessar a determinado cliente e envia correspondências em datas comemorativas. A CVC, apesar de consultar o histórico do passageiro, ainda não fez nenhuma ação personalizada, afirmando que está desenvolvendo ferramentas mais atuais e apropriadas.

Em relação às adaptações em serviços para melhorar o atendimento, verificou-se que as agências realizam ajustes em seus procedimentos intemos para minimizar os efeitos da sazonalidade. Dentre as sugestões citadas por Sasser (1976) para minimizar tais efeitos, a Stella Barros e a CVC agendam horários de atendimento, fornecem pacotes com menores preços na baixa temporada e fornecem serviços de apoio ao cliente durante o tempo de cspera, como serviços de copa e área para leitura de revistas especializadas em turismo. Ambas empresas afirmaram não contratar funcionários extras para os períodos de alta procura, alegando que os funcionários necessitam de muito treinamento antes de iniciar a operação.

Finalmente, retomando a idéia de Kotler, Bowen e Makens (1996), as agências não podem deixar de considerar como a implantação de ações que agregam valor para o cliente impacta na lucratividade. Isso significa verificar se o cliente está disposto a pagar mais pelo diferencial.

\section{Avaliando o Valor dos Serviços}

Para analisar o valor dos serviços oferecidos pelas agências de viagens solicitou-se que ambas fizessem uma classificação dos principais serviços que oferecem, indicando a opinião de seus clientes para cada serviço apresentado, de acordo com as categorias do modelo de Albrecht (1995) - serviços básicos, esperados, desejados e inesperados.

Os serviços classificados pelas agências podem ser divididos em dois grupos, o grupo de serviços relacionados diretamente à oferta do produto turístico e o grupo de serviços de apoio, que não estão relacionados à atividade - fim dessas empresas e que servem para incrementar a oferta.

Com relação aos serviços que estão diretamente relacionados à oferta turística, as agências pesquisadas posicionam-se de forma bastante similar, classificando a maioria no mesmo nível de valor. Dessa forma, os itens "passagens aéreas nacionais", "passagens aéreas internacionais", "hotéis no Brasil", "hotéis no exterior", "cruzeiros" e "excursões epacotes turísticos" são considerados por ambas como serviços básicos, visto que sua ausência praticamenteelimina a empresa do mercado.
Os itens "locação de veículos no Brasil" e "locação de veículos no exterior" são classificados pelas agências como scrviços esperados, os quais o cliente já considera como parte da prática geral dos negócios. As agências classificam "reservas para teatros, óperas ou restaurantes" como serviços inesperados, que adicionam valor além das expectativas dos clientes. Para o caso de serviços oferecidos por ambas empresas, verifica-se que apenas os itens "assistênc

"intérpretes e guias" apresentam diferenças na classificaçao segundo o modelo proposto. A Stella Barros considera os dois itens citados c

capazes de encantar o cliente. Já a CVC atribui ao item ' assıs

vistos" a classificação de serviços desejados, isto é, de atributos que o cliente valoriza, mas não espera receber, e ao item "intérpretes e guias" a classificação de serviço esperado, ou seja, de atributos que o cliente espera encontrar na oferta da empresa.

Com relação aos serviços de apoı, verıfıca-se que apesar de nao serem essenciais a compra, adicionam novas características ao processo, atribuindo valor a oferta. As agências classificam os serviços de apoio como serviços esperados ou desejados, o que aponta que são encarados como um compl

e não como essenciais (serviços básicos) ou como diferenciaıs de atendımento que encantam o cliente (serviçosinesperados). Dentre os serviços de apoio of erecidos no ambiente físico das agências, o serviço de "copa", bem como as "áreas para leitura de revistas especializadas e para projeção de vídeos" são considerados serviços esperados tanto pela CVC como pela Stella Barros. Já os serviços de "manobrista", de "empréstimo de fitas de vídeos e revistas" e de "mostruário de fotos e cartões postais" são classificados como esperados pela CVC e como desejados pela Stella Barros.

Pode ocorrer uma mudança na avaliação do valor do serviço, quando ele deixa de ser único e singular, passando a ser oferecido por muitas empresas. Assim, um serviço inesperado pode passar a desejado ou até mesmo a esperado sob o ponto de vista do cliente, se a maioria das empresas do setor o adota como parte da oferta. Tal fato dificulta a manutenção do encantamento do cliente por um longo período de tempo, principalmente quando se trata de empresas de serviços, pois nesse caso a concorrência tem mais facilidade de copiar os atributos de diferenciação.

As agências devem estaratentas para a avaliação que os clientes fazem de seu serviço de consultoria de viagens, uma vez que esse serviço tem potencial de agregar valor à oferta. O serviço de consultoria de viagens se baseia na experiência e no conhecimento que as agências detêm sobre o destino turístico e representa uma vantagem competitiva na qual deve-se buscar aprimoramento ${ }^{3}$.

\footnotetext{
3. Para mais informaç̃̃es sobre opapel de consultoria de viagens, sugere-se a seguinte leitura: CALDEIRA, Amauri.Un mercado em transformação. Estado de S. Paulo, S. Paulo, 02 nov. 1999.
} 


\section{Consideraçōes Finais}

As agências de viagens estão enfrentando grandes desafios no que se refere à adaptação ao ambiente globalizado e ao surgimento de novas tecnologias, como a Internet. Compreendendo o processo de transformação que o setor está sofrendo, algumas agências têm procurado se diferenciar no mercado por meio da prestação de serviços com excelência e da incorporação de serviços à sua oferta turística. A excelência em serviços representa muito sob o ponto de vista do cliente e garante um diferencial para a empresa. Ocliente sente-se especial e vê, noincremento do serviço oferecido, uma vantagem em utilizar os serviços da agência.

Em relação ao estudo de casos, verifica-se que as agências pesquisadas têm preocupação de estar criando, inovando e adaptando serviços para a satisfação dos clientes. Tanto a CVC quanto a Stella Barros reconhecem como factível a possibilidade de haver mudança de fornecedor por parte dos consumidores, em virtude da ampla gama de ofertas do mercado, intensificada pelo avanço da Internet. Tentando minimizar tais possibilidades, as agências oferecem vantagens, alternativas e soluções em serviços a partir da compreensão das expectativas de seu público. Constataram-se, no estudo de casos, algumas ações efetivas de melhoria e diferenciação de serviços, porém há que se explorar outros instrumentos com criatividade para que os serviços oferecidos alcancem o nível de encantamento do cliente. O esforço daCVC de diferenciar sua oferta por meio de scrviços ć pcrccbido, sobretudo, na tentativa da empresa de reduzir a espera no atendimento do cliente nas lojas. Já a Stella Barros tem maior preocupação em personalizar o atendimento do cliente, utilizando ações de pós-venda adaptadas às preferências dos passageiros. Os ajustes em serviços visando à redução dos efeitos da sazonalidade são feitos de maneira similar pelas agências, visto que utilizam recursos muito semelhantes para esse fim.

$\mathrm{O}$ valor percebido pelo cliente em relação aos serviços oferecidos, segundo o modelo de Albrecht (1995), difere em alguns pontos na avaliação das agências. Não houve distinção na classificação de serviços básicos, o que significa que as agências consideram os mesmos serviços como essenciais à oferta turística. Em relação aos serviços esperados, desejados e inesperados houve variação de respostas. A CVC assume uma postura exigente com relação à classificação dos serviços, sob o ponto de vista de seu consumidor. Verifica-se que enquanto a Stella Barros classificou uma série de serviços como inesperados, a CVC classificou-os como serviços esperados ou desejados, ou seja, enquanto a Stella Barros considera que um determinado serviço possa encantar o seu cliente, a CVC considera que esse mesmo serviçojá faz parte da prática dos negócios ou talvez possa ser apreciado pelo cliente, mas não chega a encantá-lo.

O estudo de serviços, vinculado aos conceitos de valor e de satisfação do cliente, representa importante campo para pesquisas de marketing e para o setor turístico. Acredita-se que por meio do incremento em serviços seja possível aumentar a cornpetitividade empresarial no mercado e a satisfação dos consumidores, principalmente no caso de empresas cujos serviçosconstituemo núcleoprincipal da oferta, como é o caso das agências de viagens.
ALBRECHT. Karl. 1995. Trazendo o poder do cliente para dentro da empresa: a única coisa que importa. São Paulo:

BERRY, 1995. On great service, Nova York: Free Press.

CHRISTOPHER, M.;PAYNE, A.;BALLANTYNE, D. 1991. Relationship Marketing. Institute of Marketing Professional DevelopmentSeries.

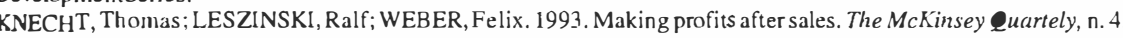
winter.

KOTLER, P.; BOWEN, J.; MAKENS, J. 1996. Marketing for hospitality and tourism. New Jersey: Prentice Hall. KOTLER, Philip; ARMSTRONG, Gary. 1998. Principios de marketing. Rio de Janeiro: Prentice Hall. KOTLER, Philip; HAIDER, Donald; REIN, Irving. 1993. Marketing places: attracting investment, industry and tourism

to cities, states and nations. New York: Fre Press.
LEVITT, Theodore. 1980. Marketing success through differentiation of anything. Harvard Business Review, p. 83-91, jan./fev.

1995. “Após a venda ter sido realizada." In: SVIOKLA, John J.; SHAPIRO, Benson. Mantendoclientes. São Paulo Makron Books.

W. .

LOVELOCK, Christopher. 1995. Product plus: produto + serviço = vantagem competitiva. São Paulo: Makron Books MACHADO, Jorge A. S. 1999. Um modelo de marketing para serviços ao cliente e sua adequaçâo na indústria automobillstica. Tese (doutorado em Administração) - Faculdade de Economia, Administração e Contabilidade da Universidade de São Paulo.

MC GOLDRICK, Peter J. 1990. Retail Marketing. Londres.

PRIDE, William; FERREL, O. C. 2001. Marketing: conceitos e estratégias. Rio de Janeiro: LTC. SASSER, W. Earl. 1976. Match supply and demand in service industries. Harvard Business Review, nov/dec.

SHETH, Jagdish; MITTAL, Banwari; NEWMAN, Bruce. 2001. Comportamentodo cliente: indoalém do comportamen lo do consumidor. São Paulo: Atlas.

SUDHARSHAN, D. 1995. Marketing Strategy: Relationships, Offerings, Timing \& Resource Allocation. Englewoo Cliffs, $N J$, Prentice Hall.

Workex source of competitive advantage. Journal of Academy of Marketing Science, v. 25, n. 2, spring, p. 142

Recebido em 8/3/02

Aprovado em 14/3/02 